\title{
A PRÁTICA DOCENTE NO ENSINO DE LITERATURA NA PERSPECTIVA DA ESTÉTICA DA RECEPÇÃO
}

\author{
Maklina dos Santos Almeida ${ }^{1}$ \\ Leonardo Chaves Ferreira ${ }^{2}$ \\ Izabel Cristina dos Santos Teixeira ${ }^{3}$
}

RESUMO: O trabalho, vinculado ao Programa Institucional de Bolsas de Iniciação à Docência (PIBID/LETRAS/UNILAB), propõe a discussão da fruição do texto literário nas escolas de ensino básico de Redenção/CE, como prática alternativa ao ensino tradicional de Literatura. De acordo com Oliveira (2016), o ensino tradicional restringe a aprendizagem dos estudantes ao formalismo das escolas literárias, dificultando as experiências sensoriais, estéticas e temáticas dos textos literários. Deste modo, buscou-se recuperar o sentido e a função social da literatura por meio da oralidade e do contato com o texto lido. O trabalho fundamenta-se na Teoria Estética da Recepção formulada por Hans Robert Jauss, na qual ocorre a interação leitor-texto. Foi realizado um Sarau Literário, atividade reflexiva alusiva ao dia dedicado à Consciência Negra para despertar o senso crítico em relação ao racismo e contribuir para a formação de leitores. No segundo momento, aplicamos um questionário estruturado para 105 estudantes acerca das aulas de Literatura. A Estética da Recepção é uma abordagem que pode vir a ser mais utilizada nas aulas de Literatura, pois utiliza métodos que propiciam maior contato com o texto literário e facilita a recepção do leitor, contribuindo para a formação de leitores.

Palavras-Chave: Literatura; Estética da Recepção; Ensino; Sarau.

\begin{abstract}
The present work, linked to the Institutional Teaching Initiation Grants Program (PIBID/LETRAS/UNILAB), aims to reflect on the fruition of the literary text as an alternative practice to the traditional teaching of literature. To do so, we will rely mainly on the postulates of Hans Robert Jauss (1967), on the "Aesthetics of Reception". In this research, we conjecture that the methods of teaching literature based on the receptional bias and the direct contact of the reader with the text contribute to a significant learning in literature and that the class limited only to the chronological information of the literary schools empties the effects of the literary experience. Methodologically, the work was divided into two stages: (1) realization of a "Literary Sarau", as a reflection on the day of "Black Consciousness", aiming to awaken the critical sense, in relation to racism, from a dynamic relationship between author, work and reader; (2) application of a questionnaire, structured for 105 students, about the classes of literature. After these steps, we proceeded to the conclusive data, related to the approach of the Aesthetics of Reception in the literature classes, by employing methods that provide greater contact of the reader with the literary text, highlighting its importance in the reading process.
\end{abstract}

Key words: Literature; Aesthetics of Reception; Teaching; Soiree.

\footnotetext{
${ }^{1}$ Graduanda em Letras-Língua Portuguesa. Universidade da Integração Internacional da Lusofonia AfroBrasileira (UNILAB); bolsista do Programa Residência Pedagógica (CAPES/UNILAB), subprojeto Letras-Língua Portuguesa-CE; voluntária no projeto de extensão Laboratório de Publicação Digital-Publicadora Palmartes; graduada em Enfermagem; especialista em Gestão em Saúde pela UNILAB. E-mail:

<maklinalmeida@hotmail.com>.

${ }^{2}$ Graduando em Letras-Língua Portuguesa pela UNILAB; bolsista do Programa de Educação Tutorial Humanidades e Letras (PETHL/Unilab) e pesquisador do Grupo de Pesquisa em Texto, Discurso e Ensino (TEDE/Unilab). E-mail: <leonardochavesferreira@gmail.com>.

${ }^{3}$ Graduada em Licenciatura em Letras pela Universidade Federal de Santa Catarina; graduada em Geologia pela Universidade Federal do Ceará (1990); mestrado em Literatura, pela Universidade Federal de Santa Catarina; doutorado em Literatura, pela Universidade Federal de Santa Catarina. Atualmente é Docente da UNILAB, dedicando-se às literaturas de língua portuguesa (portuguesa, brasileira e africanas).
} 
- Revista de Iniciação à Docência, v. 5, n. 3, 2020 -

Publicação: março, 2021 - ISSN 2525-4332

\section{Introdução}

Para as atividades de ensino em sala de aula, o Programa de Iniciação à Docência (PIBID4 - Letras-Unilab) no Ceará, tem, como um de seus objetivos, promover, na prática pedagógica, o ensino da Língua Portuguesa e de Literatura nas escolas do ensino fundamental e médio, estreitando as relações entre a universidade e as escolas da educação básica.

No âmbito da literatura, o projeto se propõe a discutir temas como a diversidade nas relações étnico-raciais e diversidades culturais (PEREIRA, 2018). Neste intuito, o grupo de bolsistas do PIBID têm realizado atividades, como a apresentação de uma sequência básica de livros de literatura de autores afro-brasileiros e africanos, tendo em vista, além das obras do cânone literário (em geral, definido pelas universidades), tratar de uma parte da literatura colocada à margem desse padrão estético.

Segundo Cosson (2011), "a sequência básica do letramento literário na escola é constituída pelas etapas da motivação, introdução, leitura e interpretação" (p. 51). Elas são explicadas a seguir:

I) Motivação é “o momento de preparar o aluno para entrar no texto". Geralmente advém de uma questão a ser solucionada ou um tema proposto pelo professor (COSSON, 2011, p. 54-55).

II) Introdução, por sua vez, é o momento da apresentação do autor e da obra (COSSON, 2011, p. 57).

III) Leitura: os procedimentos de leitura variam conforme a extensão do texto, sendo que se o texto for curto, pode ser lido em sala de aula, mas se o texto for longo pode ser lido em casa ou em um espaço para leitura na escola. E a fim de acompanhar o texto, o professor pode solicitar a apresentação dos resultados de leitura, o que o autor denominou de "intervalos". O acompanhamento da leitura visa auxiliar o estudante em suas dificuldades no processo de leitura (COSSON, 2011, p. 62).

IV) Interpretação: parte das inferências dos enunciados para a construção dos sentidos do texto, um diálogo envolvendo o autor, leitor e a comunidade. Divide-se em momento interior e momento exterior. No momento interior, ocorre a decifração do texto em palavras e trechos até chegar a apreensão global da obra após a conclusão da leitura. O momento externo é a concretização da construção de sentido pela comunidade (COSSON, 2011, p. 65).

Posteriormente à aplicação da sequência básica, foi cogitado trabalhar a literatura, por meio da realização de um sarau de poesias, com a utilização de poemas sobre o dia da

\footnotetext{
${ }^{4}$ O Programa Institucional de Bolsa de Iniciação à Docência (PIBID): incentiva e valoriza o magistério visando o aprimoramento do processo de formação de docentes para a educação básica. É programa vinculado à Diretoria de Educação Básica Presencial da Coordenação de Aperfeiçoamento de Pessoal de Nível Superior (CAPES). Para isso, o Programa oferece bolsas aos estudantes de licenciatura a fim de que exerçam ações pedagógicas em escolas públicas de educação básica.
} 
- Revista de Iniciação à Docência, v. 5, n. 3, 2020 -

Publicação: março, 2021 - ISSN 2525-4332

Consciência Negra. Deste modo, o referido grupo propôs estimular a maior participação dos estudantes nas aulas de literatura por meio da oralidade.

Sabe-se que a abordagem do ensino de literatura na educação básica tem sido questionada quanto ao seu grau de eficiência e de significação para os estudantes, frente a um cenário recorrente do estudo sistemático da história da literatura com ênfase nas categorizações rígidas de estéticas e movimentos culturais que substituem o contato prático com os textos literários em sua materialidade (OLIVEIRA, 2016, p. 55).

Neste sentido, a autora Kefalás Oliveira (2012, p. 21) chamou a atenção para a importância do contato direto dos alunos com o texto literário "Corpo a corpo com o texto em sala de aula" e Cosson (2011, p. 47) concorda que o contato direto com o texto é fundamental para a formação do leitor literário, com o foco na experiência, que é produzida pela fruição do texto e pelo movimento contínuo de leituras.

Com efeito, para Cosson (2011), a literatura é uma linguagem que consiste em três tipos de aprendizagem: a aprendizagem na experiência por meio da palavra, a qual é destaque neste trabalho; a aprendizagem sobre a literatura, que envolve os conhecimentos de história, teoria e crítica; e a aprendizagem pela leitura do texto literário, que trabalha com os saberes e as habilidades que a prática da literatura propicia aos seus usuários. No entanto, nos métodos de ensino tradicionais, há o predomínio das duas últimas aprendizagens, enquanto a primeira, que deveria ser o ponto central (por possibilitar, exatamente, a experiência do leitor com o texto, no qual, ele poderá compreender e construir a significação da aprendizagem em literatura) é ignorada.

De acordo com Kefalás Oliveira (2012, p. 21), há pouca ou nenhuma abertura para que se utilizem obras literárias e, principalmente, a poesia durante as aulas, diante do argumento de que esses textos possuem uma estrutura de natureza metafórica e subjetiva. Ou seja, ocorre o foco na análise objetiva dos textos, perdendo-se os efeitos subjetivos da leitura, o que não ajuda a formar leitores, o que deveria ser o principal objetivo das aulas de literatura. Tal como apontam Silva et al. (2016), o método inadequado de se trabalhar a poesia na sala de aula, é justamente o que desenvolve a aversão dos estudantes por esse tipo de texto literário. Portanto, deve-se repensar como tem sido o primeiro contato dos alunos com esses textos, e se existe esse contato, pois se não for algo prazeroso, os alunos os alunos não terão interesse em ler outros poemas.

De outra forma, Oliveira (2016, p. 56) expõe, em sua pesquisa, "que depois de três anos de contato com a literatura, durante o Ensino Médio, os egressos citam apenas algumas recordações mecânicas sobre características contextuais dos movimentos literários, apresentando poucas experiências literárias de leitura e apreciação do material criativo", pois, como explica Cosson (2011, p. 22) " a literatura no ensino médio resume-se a seguir de maneira descuidada o livro didático, com aulas essencialmente informativas sobre autores, características de escolas e obras, em uma organização tão impecável 
- Revista de Iniciação à Docência, v. 5, n. 3, 2020 -

Publicação: março, 2021 - ISSN 2525-4332

quanto incompreensível dos alunos, sendo raras as oportunidades de leitura de um texto integral". Nesse sentido, pode-se destacar ainda que, segundo o referido autor:

Na leitura e na escritura do texto literário é encontrado o senso do próprio ser/estar no mundo de pertencimento. A literatura revela o que se é, incentivando a desejar e a expressar o mundo pelos próprios implicados. E isto se dá porque a literatura é uma experiência a ser realizada. A experiência literária não só permite saber da vida por meio da experiência do outro, como também vivenciar essa experiência (COSSON, 2011, p. 17).

Assim, "é fundamental que se coloque como centro das práticas literárias na escola a literatura efetiva dos textos, no entanto essa leitura também não pode ser feita de forma assistemática e em nome de um prazer absoluto de ler, mas organizada segundo o objetivo da formação do aluno" (Idem, p. 23).

Esta pesquisa tem como hipóteses que os métodos de ensino de Literatura pautados no viés recepcional e no contato direto do leitor com o texto contribuem para uma aprendizagem significativa em Literatura e que a aula limitada apenas à informação e cronologia das Escolas Literárias esvazia os efeitos da experiência literária. Em perspectiva, identifica-se na Teoria da Estética da Recepção, proposta por Hans Robert Jauss (1967), o fundamento norteador para a prática em sala de aula, envolvida na realização de um sarau literário, visando apresentar a temática da consciência negra em uma turma de $3^{\text {a }}$ série do ensino médio e, desta forma, refletir, a partir de um questionário aplicado, como a materialização do texto literário e a oralidade desses textos, sejam em prosa ou em poesia, podem despertar o interesse dos estudantes pela leitura.

\section{A Estética da Recepção, de Hans Robert Jauss}

De acordo com Zaponne (2009, p. 156), a Estética da Recepção se apresenta para o debate estético na década de 1960, se enquadrando na moderna teoria literária, na qual, entre a relação - autor, texto e leitor -, o leitor passa a ser considerado o elemento principal nos processos de leitura, pois codifica o sentido e amplia o seu significado, com base em suas experiências de vida, leituras anteriores e período histórico.

Assim sendo, a Estética da Recepção é uma estética fundamentada na experiência dos leitores. Sua importância central são os efeitos do texto provocados em quem lê, que poderão ser sentidos, se existirem leitores. Portanto, ela propõe que o caráter artístico de um texto literário advém das sensações que este possa despertar. Além disso, Jauss sugere que a história da literatura também seja pensada sob o ponto de vista recepcional, uma vez que, segundo o referido teórico, a história literária se limita a uma noção historiográfica, baseada unicamente na cronologia e no encadeamento de obras e autores, classificados de acordo com as características comuns e agrupados nas escolas literárias (ZAPONNE, 2009, p. 155-156)

Porém, contrariando a assertiva acima mencionada, o enfoque no viés recepcional seria baseado nas produções de significação do público leitor de cada época (ZAPONNE, 2009, p. 155). Assim, aparentemente, Jauss, não desvalorizava os estudos da História da 
Literatura. Ele compreendia a importância do conhecimento do cânone literário, porém a Estética da Recepção concebe a associação entre história e literatura como interpretação que depende da recepção dos textos literários pelos diferentes públicos em suas diversas épocas (ZAPONNE, 2009), dado que, como afirma Cosson (2011), "a interpretação é um diálogo que envolve autor, leitor e comunidade e depende do que escreveu o autor, leu o leitor e das convenções que regulam a leitura em uma determinada sociedade, tendo como limite o contexto" (p. 41).

\section{1 - Teses da Estética da Recepção}

A Estética da Recepção, em linhas gerais, é pautada em sete teses: 1) a obra literária não é atemporal e não apresenta um mesmo aspecto ou significado em todos os tempos. Essa tese contrapõe-se a ideia de monumentos da literatura, ao propor uma dinamização de significados construídos pelo público leitor e ao incorporar o conceito de "acontecimento literário". Este, segundo Jauss, é diferente de um acontecimento histórico, pois o acontecimento literário não é um fato documentado e não existe por si mesmo; é portanto, um ato de recepção, uma vez que o acontecimento literário só tem implicações se a recepção do texto propagar-se para leitores posteriores; 2) toda experiência ou acontecimento literário pressupõe um saber prévio, isto é, compreende os sistemas históricos-literários e de vida que o leitor possui para incorporar a nova leitura ao seu repertório literário e deste modo, Jauss introduz o conceito de horizonte de expectativa, que pode ser ampliado, à medida que o leitor realiza outras leituras; 3) A terceira tese reforça o conceito de horizonte de expectativas, no qual a obra possui o seu maior valor artístico, quando quebra as expectativas convencionais e de referências já conhecidas pelos leitores e, consequentemente, novos modelos são incorporados ao sistema literário de referência; 4) o modo como um texto é lido e interpretado é afetado pelo processo histórico; 5) o conceito de mediação entre as obras incorpora o caráter diacrônico da história literária, ou seja, aquilo que as obras podem legar para os públicos posteriores, contraria a pura dicotomia entre o velho e novo, que se baseia na lógica temporal do surgimento de uma obra; 6) a historicidade da literatura se revela nos pontos de interseção entre diacronia e sincronia, ao considerar as sucessivas recepções de um texto (diacronia). É nesses pontos de interseção que se pode obter o horizonte de expectativa, para classificar a obra como atual ou inatual; 7) a importância dos efeitos estéticos, sociais, éticos e psicológicos que a literatura é capaz de suscitar em seus receptores (ZAPPONE, 2009, p. 158-161)

Há que se considerar que toda teoria apresenta limitações. No caso da Estética da Recepção, a teoria direciona-se a um público de leitores mais especializados, por terem algum conhecimento estético literário, aporte maior de temáticas e de gêneros, o que dificulta as condições de maior participação de um público com horizonte menor de expectativas de leitura (ZAPONNE, 2009, p. 162). Mas, é uma teoria que se adequa ao objetivo de formar leitores, pois tem como razão existencial, o papel do leitor em seu letramento literário, a partir do contato integral com a obra. 
- Revista de Iniciação à Docência, v. 5, n. 3, 2020 -

Publicação: março, 2021 - ISSN 2525-4332

Diante da limitação apresentada, buscou-se relacionar a Estética da Recepção com a sequência expandida, que consiste em uma "didática posterior à sequência básica de apresentação, da obra e do autor, para a segunda interpretação, cujo objetivo é a ultrapassagem do limite de um texto para outros" (COSSON, 2011, p. 94), isto é, a intertextualidade literária e, deste modo, pode ser alcançado um maior público de leitores sob a ótica da Estética da Recepção.

A partir do Programa de Iniciação à Docência (PIBID) de extensão nas escolas, foi possível a priori observar e refletir sobre o lugar da Literatura nos livros didáticos e a metodologia proposta para isso, o que resultou na busca de alternativas mais práticas de ensino da Literatura a partir de um direcionamento teórico.

\section{Aspectos metodológicos do trabalho realizado na sala de aula}

Como apresentado anteriormente, a base teórica da investigação fundamenta-se na Estética da Recepção. Nesse sentido, o nosso principal foco é direcionar a análise na busca da relação entre texto e leitor, entendendo que a literatura é uma linguagem que consiste em uma "aprendizagem na experiência por meio da palavra" (COSSON, 2011, p. 47). Assim, de acordo com o objetivo estabelecido neste trabalho, a pesquisa adotou uma natureza de base qualitativa e quantitativa. Lembrando que ambos os conceitos de pesquisa se complementam, configuramos a metodologia "quali-quanti" de acordo com o que afirmam Minayo e Sanches (1993, p. 247):

A relação entre quantitativo e qualitativo, entre objetividade e subjetividade não se reduz a um continuum, ela não pode ser pensada como oposição contraditória. Pelo contrário, é de se desejar que as relações sociais possam ser analisadas em seus aspectos mais "ecológicos" e "concretos" e aprofundadas em seus significados mais essenciais. Assim, o estudo quantitativo pode gerar questões para serem aprofundadas qualitativamente, e vice-versa.

Sobre a metodologia de pesquisa qualitativa, Chizzotti (2011) afirma que ela:

implica uma partilha densa com pessoas, fatos e locais que constituem objetos de pesquisa, para extrair desse convívio os significados visíveis e latentes que somente são perceptíveis em um texto, zelosamente escrito, com perspicácia e competência científicas, os significados patentes ou ocultos do seu objeto de pesquisa (p. 28-29).

Esse tipo de pesquisa se mostrou de grande relevância para o desenvolvimento deste trabalho, tendo em vista que ela tem a capacidade de identificar e analisar dados que não podem ser mensurados numericamente. Dessa forma, o trabalho pautado na hipótese da materialização do texto literário na aula de Literatura busca a sua compreensão, a partir de um método indutivo que, segundo Oliveira (2005, p. 16), manifesta-se quando sua aplicabilidade compreende a observação e a experimentação dos fenômenos estudados. Para efeito deste trabalho, esses fenômenos possuem a sua significação, a partir da leitura interpretada, possibilitada, pelos sentimentos e efeitos estéticos do texto, junto às vivências e as experiências anteriores do leitor. 
- Revista de Iniciação à Docência, v. 5, n. 3, 2020 -

Publicação: março, 2021 - ISSN 2525-4332

O uso de questionários para testar as hipóteses resultou em dados coletados na escola, com 105 alunos de um total de 145 estudantes, correspondendo à percentagem de $72,4 \%$ do total de estudantes da escola, considerando-se uma boa amostragem.

Sobre esse método, Fortin (2003) ressalta: “investigação quantitativa é um processo sistemático de coleta de dados observáveis e quantificáveis. É baseado na observação de fatos objetivos de acontecimentos e de fenômenos que existem independentemente do investigador" (p. 22). Assim sendo, a aplicação dos questionários versando sobre as aulas de Literatura aos alunos, foi realizada para que se obtivesse uma melhor compreensão do objeto de estudo e da percepção do ambiente escolar sobre texto literário.

Atentando-se ao que já foi dito, cabe ainda ratificar que o desenvolvimento desse estudo partiu de uma técnica bibliográfica que, segundo Gil (2010) encontra sua vantagem em "permitir ao investigador a cobertura de uma gama de fenômenos muito mais ampla do que aquela que poderia pesquisar diretamente" (p. 50). Por meio dessa técnica bibliográfica de pesquisa, se consegue apurar um encadeamento maior de fatos, com base em livros, artigos e dissertações.

No tocante ao contexto de aplicação da pesquisa, esta vinculou-se ao PIBID, no subprojeto Letras/Unilab/Ceará, na Escola Estadual Padre Saraiva Leão, situada no município de Redenção/CE. Um dos objetivos desse sub-projeto relaciona-se ao ensino de leitura com foco em literatura. Assim sendo, o subprojeto se compromete e realiza uma ação contínua de inserção de atividades frequentes como leituras, contações de histórias e declamações de poesias, com a realização de oficinas de ilustração a partir de textos repassados oralmente para os alunos.

\section{1 - As literaturas trazidas às salas de aula}

Conforme definições do planejamento e dos objetivos estabelecidos pelo referido subprojeto, foram organizadas apresentações para uma oficina de (re)apresentação aos alunos das literaturas africanas e afro-brasileiras. Foi abordada primeiramente a literatura africana, em si, e suas principais características. Esse primeiro momento foi mediado por discentes acadêmicos de Letras da UNILAB, estrangeiros (africanos). Eles optaram por trazer os aspectos importantes da literatura de Angola, Guiné-Bissau e Moçambique. Logo após essa etapa, foi dada visibilidade à literatura afro-brasileira, trazendo "O Cortiço" (Aluísio de Azevedo, século XIX) e o poema “Olhos D'água” (Conceição Evaristo, século $\mathrm{XXI}$ ), tentando mostrar dois aspectos diferentes da discriminação racial, em épocas distintas. A escolha desses autores, no entanto, não foi feita no sentido de refutar o cânone literário, e sim, relacionar as ideias que existem nas obras canônicas com outras literaturas mais afastadas desse padrão, tendo sempre em vista a Estética da Recepção, pois Jauss considera: que a qualidade ou o valor de uma obra literária não podem ser medidos ou apreciados nem a partir das condições históricas e biográficas de sua origem nem do lugar que ela ocupa no desenvolvimento de um gênero (ZAPONNE, 2009, p. 156). 
Dessa forma, lembrando, conforme Silva, Fransuelen et al. (2017, p. 152), que "o Sarau é um local no qual se transmite conhecimento, tendo a capacidade de participar do processo de construção do pensamento do indivíduo, em vários aspectos" foi proposto aos alunos o objetivo de realizar entre eles, em sala de aula, um pré-sarau versando sobre as literaturas africanas e afro-brasileiras. Na semana seguinte, foi realizada na turma um sarau literário local, em que se efetuaram leituras de autores africanos e afro-brasileiros, tendo sido apresentados, entre outros, os seguintes textos: "Eu-Mulher" (Conceição Evaristo), "O Navio Negreiro" (Castro Alves), "Mão da Limpeza” (Chico Buarque) e "Racismo é Burrice" (Gabriel, O Pensador).

A metodologia de trabalho tomou por base as ponderações de Cosson (2011), norteadoras da atividade do sarau, ressaltando o que ele denomina "sequência expandida" que se centra "na formação de um leitor cuja competência a mera decodificação dos textos, de um leitor que se apropria de forma autônoma das obras e do próprio processo da leitura, de um leitor literário, enfim" (p. 120).

Ao relacionar a Estética da Recepção com a "sequência expandida", foi dada visibilidade à segunda tese de Jauss, a qual, segundo Zaponne (2009), explica a experiência literária do leitor que pressupõe um conhecimento prévio, que funciona como conjunto de saberes, tanto literários quanto da própria vida. A "sequência expandida" leva em conta justamente esse aspecto, em suas etapas de execução, principalmente a primeira, chamada de "motivação". Essa etapa consiste em uma atividade de preparação, de introdução dos alunos no universo do livro a ser lido, ou da poesia a ser recitada. Assim, se evidencia o conhecimento prévio e experiencial do aluno.

Nesta etapa de realização não foram ignoradas as Orientações Curriculares para o Ensino Médio, realizadas com o objetivo de "formar o leitor literário, melhor ainda, de 'letrar' literariamente o aluno, fazendo-o apropriar-se daquilo a que tem direito" (BRASIL, 2006, p. 54), exercitando o próprio direito à literatura e a sua capacidade de aguçar, não só a criticidade, mas, também, a humanidade do indivíduo, conforme lembra Antônio Cândido (1995), para quem a "literatura desenvolve em nós a quota de humanidade na medida em que nos torna mais compreensivos e abertos para a natureza, a sociedade, o semelhante" (p. 249).

\section{Resultados e discussão}

\section{1 - Percepções acerca da realização do sarau literário em sala de aula}

A partir da primeira etapa de motivação, que consistiu na "sequência expandida" apresentada em sala de aula, as obras literárias selecionadas retratavam temas como a discriminação racial, social, pobreza e injustiças, bem como os poemas de resistência a essas realidades, a fim de despertar o senso crítico e o prazer pela leitura, ao trazermos temas ainda recorrentes na realidade atual.

Dando destaque às obras em prosa, observou-se que a exposição de "O mulato" (1881), "Casa de Pensão" (1884) e "O Cortiço" (1890), de Aluísio Azevedo, bem como a 
ação de levar o livro "O Cortiço" para a sala de aula para ser manuseado pelos alunos, foram mínimas ações que despertaram maior envolvimento desse público com a aula, por propiciar uma rotina diferenciada.

O ato de narrar as estórias, como a enredo de "O Mulato", marcado pelo preconceito racial, hipocrisia, violência e a morte da personagem Raimundo, suscitou sentimentos como surpresa e espanto, o que corrobora com o conceito de horizonte de expectativas, retratados na Estética da Recepção de Jauss e também no livro "Letramento Literário", de Cosson. Esta obra, apesar de ter sido escrita no final do século XIX, ainda provoca o choque do leitor perante os finais trágicos apresentados. Com isso, reforça-se a importância da "sequência expandida", para que os leitores incorporem mais modelos de referências ao seu repertório literário. Contudo, para além da oportunidade de repassar conhecimento, o objetivo foi atingido por provocar efeitos perceptuais nos interlocutores, o que possibilita a afirmação de que a aula de Literatura deve promover o efeito estético o qual é provocado quando há a significação do texto, e que como defende Cosson (2011), "quer seja a leitura de uma obra clássica ou contemporânea, o importante é que seja atual para fazer sentido para o leitor, independente da época em que foi escrita" (p. 34).

Ainda, concernente à primeira etapa da "sequência expandida", foram apresentados outros autores e suas respectivas obras. Neste caso, tratamos de autores menos recorrentes no ensino de Literatura. Entre eles, o poema "Havemos de Voltar", do escritor e ex-presidente angolano Antônio Agostinho Neto, membro do Movimento Popular de Libertação de Angola (HORING, 2015).

O foco do referido poema incide nos movimentos de partida e de regresso do sujeito poético em sua terra natal (FERREIRA, 2012, p. 3), ao passo que poemas que também trataram sobre a questão da escravidão, como o exemplo o do poeta Castro Alves, conhecido como o "poeta das causas humanitárias", mostra a temática com outra intencionalidade: a de um discurso salvador dos oprimidos (CANDIDO, 1981, p. 241). Desta forma, é importante levar poemas e obras literárias que contrastem intencionalidades variadas acerca de uma mesma temática em debate para que os estudantes percebam que a literatura é um espaço de troca com o outro e os seus valores. Nesse sentido, Cosson (2011, p. 17) afirma que a literatura é:

A incorporação do outro em mim sem renúncia da minha própria identidade e é nesse exercício promovido pela literatura que podemos ser outros, podemos viver como os outros, romper os limites do tempo e do espaço de nossa experiência, e ainda sermos nós mesmos. E por esse motivo, interioriza-se com mais intensidade as verdades dadas pela poesia e pela ficção (p. 17).

A partir dessa declaração, é possível enfatizar a necessidade de uma aula que estimule o contato com as obras, por meio da leitura e também da oralidade, como realizado na "sequência expandida" e no sarau, pois apenas com a ação do leitor, de recepcionar os textos literários, ele constrói significados e, a partir dessa experiência, a literatura produz, desde "efeitos estéticos a efeitos éticos, sociais e psicológicos que, por fim, como postulado por Jauss (1994, p.52 apud Zaponne, 2009) em sua sétima tese, são capazes de romper com a percepção comum que os leitores têm da vida cotidiana, ao permitir-lhes antecipar possibilidades ainda não concretizadas e expandir, até o repertório de comportamento social frente a novos desejos, pretensões e objetivos, instigados por novos mundos apresentados pela literatura, o que resulta na abertura de novas trajetórias para experiências futuras" (p. 161). Ou seja, a poesia e a prosa literária têm um poder 
transformador no indivíduo, ao possibilitar que este leia o mundo. Esse mesmo conhecimento de mundo contínuo poderá, por sua vez, suscitar diferentes interpretações do mesmo texto, pelo mesmo leitor, à medida que este significa e ressignifica as palavras, com base em suas experiências de vida posteriores, condicionando outras recepções, a partir da recepção inicial, por possibilitar outras visões sobre um mesmo objeto.

A dinâmica da "sequência expandida" levou autores variados para a aula, entre eles, do cânone, representado por Aluísio de Azevedo; não canônica (periférica), como a autora Maria Carolina de Jesus e Conceição Evaristo e também estrangeiros, como o autor Antônio Agostinho Neto. Foi recitado, por exemplo, o poema "Olhos d'água", do livro "Poemas de Recordação e Outros Movimentos", da autora Conceição Evaristo (2008).

É possível observar que o fato de ser um poema de uma autora que os alunos da escola desconheciam, e a exposição em slides do livro, despertou a atenção dos estudantes presentes, na turma, ao mesmo tempo, em que a narrativa suscitou comoção, por abordar temas como a luta diária da mulher negra brasileira, a pobreza, a fome e a retomada da ancestralidade africana.

Desta forma, considera-se que a escolha de textos literários mais próximos da realidade social e que possuam uma linguagem mais compreensível, é capaz de envolver mais ao público estudantil, pois o texto possui uma comunicação mais fluida, ao mesmo tempo, em que a escrita de Conceição Evaristo compõe-se, como explica Alós (2011, p. 1-2) de elementos de subjetividade, de identidade, ao articular em sua poética às questões relativas à representações de gênero, raça e classe social, bem como, e sobretudo, da mulher negra brasileira, marginalizada pela condição social e cor da pele. Portanto, o discurso de Conceição Evaristo e de autores afro-brasileiros da literatura periférica, é de resistência, no sentido de reivindicar a escrita de si, ao buscar pela própria voz o resgate da sua memória, apagada pelo silêncio histórico imposto aos afro-descendentes no Brasil.

Neste contexto, pode-se inferir que esse poema, por recuperar a subjetividade, possuiu maior recepção pelos estudantes, pelo que é possível atribuir ao grau de identificação destes, com a forma como o ele foi apresentado. Desta forma, leituras que aproximam os leitores, que se sintam enquadrados ou atraídos pelo mundo simbólico do autor, aparentemente geram os efeitos esperados: estéticos, sociais e psicológicos. Oliveira (2016, p. 57) propõe trabalhar os textos literários a partir de temas geradores propostos pelos próprios estudantes, por considerar uma alternativa substantiva para fornecer elementos de transformação para o ensino da Literatura.

Referente à segunda etapa, a do "Sarau Literário", foram trabalhados os seguintes poemas: "Canto I" e "Canto V", do poema "O Navio Negreiro", do poeta Castro Alves (1870), e "A Mão da Limpeza", de Chico Buarque (1984) e "Eu- Mulher”, da Conceição Evaristo (2008).

O sarau literário foi um momento prazeroso e também educativo, no qual se trabalhou, do poema clássico à música. A declamação do poema "O Navio Negreiro" assemelhou-se a uma contação de estória; o poema "Eu-Mulher” valorizou o papel social das mulheres, como se metaforizasse a capacidade de gerar vida com a mãe-África, berço da civilização. No tocante à música, foi valorizada como um elemento contemporâneo, muito presente na vida dos jovens. Desta forma, a atividade buscou dar vida à poesia, por meio da apresentação em grupo e da leitura interpretativa e recitação em voz alta, porque os versos precisam ser sentidos. 
De acordo com Silva et al. (2016, s. p) a leitura em voz alta possibilita o desenvolvimento da oralidade literária e oportuniza o debate. Nesse sentido, "a leitura em voz envolve o corpo de quem lê e de quem escuta, sendo possível realizar várias leituras, com entonações diferentes, o que desencadeia múltiplas interpretações. O que o texto literário faz no corpo de quem o lê?" (OLIVEIRA, 2009, p. 11). Segundo a referida autora, a leitura sempre provoca algo no leitor e não é possível deixar esse propósito de lado nas aulas de Literatura.

Na sequência, por percepções visuais, verificou-se que os estudantes continuaram concentrados durante a realização do sarau, bem como participaram, com breves perguntas sobre os poemas "O Navio Negreiro" e a letra da música "A Mão da Limpeza", de Chico Buarque, ou seja, a atividade suscitou uma motivação inicial, no entanto, não resultou no posicionamento crítico dos estudantes, possivelmente, devido ao tradicionalismo instaurado há anos no sistema educacional, que, aparentemente, compreende a quantidade de informação como qualidade do ensino. E mais ainda: a carga horária reduzida para as aulas de Literatura acaba dificultando a fruição dos textos e a significação destes para a formação escolar e pessoal. Com isso, os estudantes não se sentem, muitas vezes, preparados para participar do debate sobre essas temáticas. Nesse caso, Violin (2013) destaca que "a política governamental privilegia o quanto o aluno entende e assimila de um texto e não o quanto frui o texto" (103).

Com base nas reflexões acima mencionadas sobre a importância de uma aula de literatura que valorize o valor estético dos textos literários, por meio dos sentidos e efeitos que estes produzem nos leitores, foi aplicado um questionário com questões objetivas e estruturadas, a fim de se obter o posicionamento dos estudantes da escola acerca da forma como são trabalhadas as aulas de literatura e como eles gostariam que fossem, conforme suas percepções.

\section{2 - Aplicação do questionário aos estudantes da Escola Padre Saraiva Leão acerca das metodologias do Ensino da Literatura}

Participaram da pesquisa 105 estudantes de três turmas $\left(1^{\circ}, 2^{\circ}\right.$ e $3^{\circ}$ anos) da Escola Estadual EEMTI Padre Saraiva Leão. Dentre eles, 54,3\% são adolescentes do sexo feminino e 45,7\%, adolescentes do sexo masculino, como visto no Gráfico 1:

Gráfico 1 - Quantidade de entrevistados por sexo (Fonte Google forms).

SEXO

105 respostas

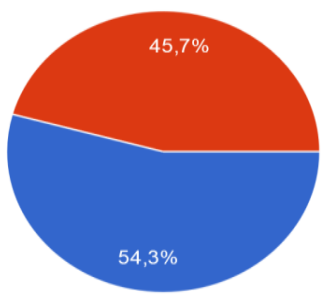

Mulher

Homem

Por sua vez, o segundo gráfico expressa a presença da poesia nas aulas de Literatura, considerando a referida Escola. 
- Revista de Iniciação à Docência, v. 5, n. 3, 2020 -

Publicação: março, 2021 - ISSN 2525-4332

Gráfico 2 - Utilização da poesia nas aulas de Literatura. (Fonte: Google Forms).

Na sua aula de literatura se trabalha poesia?

105 respostas

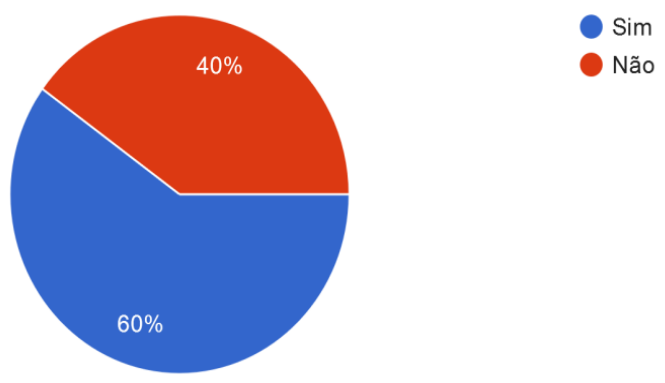

Como expresso, 60\% dos estudantes, ou seja, 63 alunos, afirmaram que os professores trabalham poesia nas aulas de literatura, mas cerca de $40 \%$ dos alunos, isto é, um número de 42, uma quantidade considerável do público estudantil da Escola, afirmaram que a poesia não é trabalhada nas aulas de Literatura. Uma das explicações para isto é o fato de que ao passar na turma de $1^{\circ}$ ano para entregar os questionários, eles afirmaram que tiveram pouco ou nenhum contato com a literatura no $1^{\circ}$ semestre de 2019 , desta forma, as turmas de $2^{\circ}$ ano e $3^{\circ}$ ano têm um contato maior com a área de conhecimento.

Gráfico 3 - Métodos de utilização dos textos poéticos em sala de aula. (Fonte Google forms).

De que forma é trabalhada a poesia em sala de aula? 105 respostas

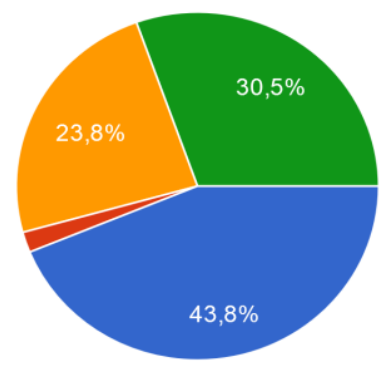

Leitura coletiva do poema em sala de aula

Sarau, música ou teatro.

Leitura completa de obras literárias

Somente leitura do livro didático

Das 105 respostas obtidas dos estudantes, considerando os três anos do ensino médio, identificamos que, segundo $43,8 \%$ dos alunos, o poema é trabalhado com leitura coletiva em sala de aula; 30,5\% manifestaram que ocorre somente a leitura do livro didático, ao passo que as práticas de leitura completa de obras literárias alcançaram apenas 23,8\% das respostas; as atividades como sarau, música ou teatro, 1,9\%; ou seja, essas atividades são quase inexistentes na prática de ensino. Com base nesses resultados, relacionou-se a 
- Revista de Iniciação à Docência, v. 5, n. 3, 2020 -

Publicação: março, 2021 - ISSN 2525-4332

resposta de que para $36,2 \%$, as aulas de literatura são cansativas, como demonstra o resultado exposto no Gráfico 4.

Gráfico 4 - Satisfação dos alunos em relação às aulas de Literatura (Fonte: Google Forms)

Você acha cansativa ou exaustiva a aula de literatura?

105 respostas

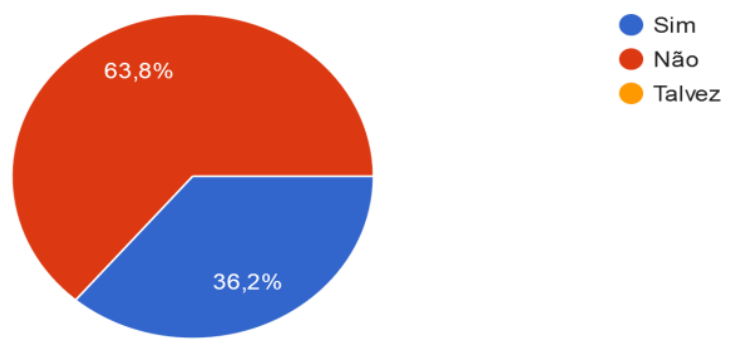

Deste modo, é possível inferir que uma das possíveis causas para essas aulas serem consideradas pouco atrativas sejam as metodologias mais frequentes como a leitura coletiva do poema em sala de aula, somada somente à leitura do livro didático, que impossibilitam a percepção do efeito artístico e dificultaram a apropriação e construção do sentido da literatura para os estudantes.

Entretanto, para a maioria dos estudantes $(63,8 \%)$ as aulas de literatura não são cansativas, o que nos leva a refletir que as aulas mais tradicionais também apresentam relevância na escola. Contudo, é preciso a inclusão de outras atividades para a construção do saber literário dos estudantes, uma vez que para 36,2\% deles, um número significativo, as aulas de literatura apresentam problemas.

No tocante à pergunta sobre como os estudantes consideram que seriam métodos melhores para as aulas de literatura, observe-se o Gráfico 5:

Gráfico 5 - Metodologias esperadas para as aulas de Literatura.

Como a aula de literatura poderia se tornar melhor?

105 respostas

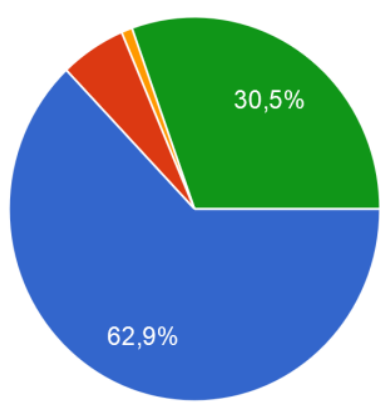

Com poesia (sarau), música, teatro

Com leitura guiada

Com livro didático

Leituras completas de obra literária e debates em sala 
Como se nota, a maioria dos alunos (62,9\%) marcaram a opção poesias (sarau), música e teatro. As leituras completas de obras literárias para a posterior realização dos debates em sala foram assinaladas por 30,5\% dos participantes. Portanto, as atividades mais votadas pelos estudantes são justamente aquelas menos realizadas na escola, o que comprova que a Estética da Recepção é uma abordagem da literatura que apresenta um grau de aceitabilidade e valorização pelos estudantes, por possibilitar o contato direto com o texto literário e maior interação e expressão artística, o que propicia o prazer da leitura.

As atividades que envolvem o sarau, a música e o teatro trabalham com pontos em comum, como a oralidade individual, entonação e a interpretação, ou seja, com o uso criativo da voz. Nesse sentido, Oliveira (2012) chama atenção para o fato de que, após a leitura silenciosa, a leitura em voz alta deve ocorrer de forma individual, isto é, respeitando o turno da fala de cada pessoa no grupo, a fim de permitir ao ouvinte e ao emissor, a experiência sensorial de diferentes entonações, enriquecendo, deste modo, a interpretação. Nesse sentido, Oliveira (2012, p.352-353) afirma:

A voz poética é singular, porque primeiro, não informa, não é veículo de uma
mensagem que atravessa, mas se faz ouvir e sentir enquanto corpo, presença
expressiva que se impõe no tom, no peso das palavras, nos intervalos de silêncio
e em segundo lugar, exige atenção, concentração e duração no instante em que
é pronunciado, ao resgatar, nesse momento, a performance, a mensagem e o
intérprete, seja ele o que emite ou o que recebe e reatualiza a voz do outro- da
fugacidade do tempo, que tudo devora e consome no universo do pragmatismo.

No sarau literário também foram utilizadas as letras de músicas como recursos estéticos: "Mão da Limpeza", de Chico Buarque, e "Racismo é Burrice”, de Gabriel, o Pensador, pois a música, assim como a literatura, é uma linguagem artística. Trata-se de um gênero híbrido, ou seja, de caráter intersemiótico, resultado da união da linguagem verbal e a musical que possui ritmo e melodia, assim como a poesia, gênero que também possui entonação e ritmo (COSTA, 2010, p. 118). Dessa forma, justifica-se o uso da música no sarau, porquanto, ela possibilita o prazer sensorial e estético em uma interação pluridirecional dos elementos autor-cantor-personagens-melodia-ouvinte genérico-ouvinte individual etc. Assim, os estudantes tornam-se ouvintes críticos de canções e, portanto, capazes de perceber os efeitos do sentido do texto (COSTA, 2010, p.131).

Do exposto acima, a partir da experiência com o sarau literário e da aplicação do questionário junto aos estudantes, inferimos que aulas de literatura pautadas na perspectiva da Estética da Recepção, pode ser uma abordagem a ser implementada e utilizada com maior frequência na prática do ensino de Literatura, por despertar maior interesse dos estudantes, uma vez que se utiliza de métodos que propiciam maior contato com o texto literário e a sua recepção. Com isso, as aulas tornam-se significativas, por motivarem a sensibilidade do leitor e ouvinte para os efeitos estéticos, éticos e sociais do texto, além de despertar o senso crítico dos estudantes, uma vez que é necessário, assim como afirmava Candido (1995), fazer com que a literatura humanize, fazendo seus leitores vivenciarem diferentes realidades e situações, uma vez que a humanização nada mais é que 
"o processo que confirma no homem aqueles traços que reputamos essenciais, como o exercício da reflexão, a aquisição do saber, a boa disposição para com o próximo" (p. 249). Nesse contexto, enfatizamos a $7^{\mathrm{a}}$ tese da Estética da Recepção, destacando o texto literário como produtor de efeito estético e gerador de efeitos éticos, sociais e psicológicos nos leitores. Desse modo, faz-se necessária a utilização de uma abordagem de ensino que suscite a consciência do conhecimento literário na vida prática dos estudantes e leitores.

\section{Considerações finais}

A metodologia desse trabalho se norteou pela Teoria da Estética da Recepção, direcionando a análise literária na busca da relação entre texto e leitores. Primeiramente, foi observada essa relação e, em seguida, sua aplicação, tendo, como partida, o questionário que constituiu um corpus sólido, envolvendo significativa parte dos discentes da escola em que em que se deu a realização das etapas de trabalho. Basicamente, nossas conclusões são as seguintes: a) as causas para as aulas serem consideradas pouco atrativas estão relacionadas às metodologias mais frequentes, como a leitura coletiva do poema em sala de aula, que é somada somente ao uso do leitura do livro didático, que impossibilitam a percepção do efeito artístico e dificultam a apropriação e construção do sentido da literatura para os estudantes; b) inclusão necessária de outras atividades para a construção do saber literário dos estudantes, uma vez que a aula de literatura é cansativa para uma parte considerável dos alunos; c) a Estética da Recepção é uma abordagem que apresenta um grau de aceitabilidade e valorização pelos estudantes, o que possibilita o contato direto com o texto literário e maior interação, propiciando o prazer da leitura.

Desse modo, a pesquisa confirmou a primeira hipótese do trabalho de que o contato direto com o texto, baseando-se na experiência e na interatividade, é fundamental para a formação do leitor literário, pois, no sarau, percebeu-se uma maior participação dos alunos e o questionário aplicado nos permitiu obter dados interessantes. Esses dados mostraram, por exemplo, um favorecimento dos estudantes a um ensino de literatura voltado também à interatividade, que permite, justamente, a fluidez do texto literário e poético, por meio da música, do teatro e da arte em si. Além desse fato, os dados coletados mostram que o foco na análise objetiva, cronológica e categórica do texto literário, esvazia os efeitos experienciais da leitura, tornando as aulas fadigosas e não ajudando na formação de leitores. Esses dados são ratificados pela $5^{\text {a }}$ tese da Estética da Recepção. Por isso, uma parte significativa dos alunos, através do questionário, mostraram que acham as aulas de literatura cansativas (36,2\%); a isso, pode-se atribuir a cronologia das aulas de literatura que se baseiam, simplesmente, na categorização das escolas literárias. Esse fato, que se constata no questionário aplicado, não permite o "efeito estético", e é esse efeito que possibilita o maior interesse dos alunos, quando eles "degustam" a aula de literatura, entendendo o seu verdadeiro sentido. Mas deve-se observar, também, que a maioria dos alunos $(63,8 \%)$ não acham a aula tradicional de literatura cansativa. No entanto, é possível, para uma maior interação do aluno com o texto literário, agregar mecanismos à 
- Revista de Iniciação à Docência, v. 5, n. 3, 2020 -

Publicação: março, 2021 - ISSN 2525-4332

metodologia tradicional que possibilitem a experiência sensível com os mais diversos textos literários.

Outra questão importante é observar que os alunos da escola queriam aulas de literatura com sarau, música ou teatro ( $62,9 \%$ dos estudantes), mas isso era o que menos acontecia. Apenas 1,9\% dos alunos confirmaram a poesia trabalhada através de sarau, música ou teatro. Isso enfatiza que é necessária a prática de aulas que levem em consideração a recepção dos alunos, no modo como eles vão sentir e, não somente ler o texto poético.

\section{Referências}

ALÓS, A. P. Recordações de uma Afro-Brasileira e outros movimentos. Revista Escrita, Rio de Janeiro, n. 12, 2011.

ALVES, A. F. de C. O navio negreiro.

Disponível em: http://www.dominiopublico.gov.br/pesquisa/DetalheObraForm.do?select_action=\&co_obra=1786 Acesso: 15 abril 2020.

BRASIL. Ministério da Educação. PCN - Ensino Médio: Orientações Curriculares para o Ensino Médio. Linguagens, códigos e suas tecnologias. Brasília/DF: Secretaria da Educação Média e Tecnológica, 2006

BUARQUE, C. A mão da limpeza. Disponivel em: https://www.letras.com/chico-buarque/1228782/ Acesso em: 15 de abril de 2020

CÂNDIDO, A. O direito à literatura. In: Vários escritos. São Paulo/SP: Duas Cidades, 1995.

CÂNDIDO, A. Poesia e oratória em Castro Alves. In: CÂNDIDO, A. Formação da literatura brasileira, v. II, cap. 5, 6. ed. Belo Horizonte/MG: Itatiaia, 1981, p. 241-255.

CHIZZOTTI, A. Pesquisa qualitativa em Ciências Humanas e Sociais-Estudo de caso. Editora Vozes, 2011.

COSSON, R. Letramento literário. São Paulo/SP: Contexto, 2011.

COSTA, N. B. As letras e a letra: o gênero canção na mídia literária. In: DIONISIO, A. P.; MACHADO, A. R.; BEZERRA, M. A. (Org). Gêneros textuais e ensino. São Paulo/SP: Parábola Editorial, 2010, p.117-132.

EVARISTO, C. Poemas da recordação e outros movimentos. Olhos d'água. Belo Horizonte/MG: Nandyala, 2008, p. 15-19

FERREIRA, L. da C. A utopia das letras de Agostinho Neto. Revista Eletrônica de Estudos Literários, Vitória, [s. n.], ano 8, n. 11, 2012.

FORTIN, M. F. O processo de investigação: da concepção à realização. São Paulo/SP: Atlas, 2010.

GIL, A. C. Métodos e técnicas de pesquisa social. 6.ed. São Paulo/SP: Atlas, 2008. 
- Revista de Iniciação à Docência, v. 5, n. 3, 2020 -

Publicação: março, 2021 - ISSN 2525-4332

HORING, J. da S. Os movimentos de Libertação Nacional em Angola: Trajetória Política, Guerra Civil e Impactos sobre a construção do Estado (1975-2002). Universidade Federal do Rio Grande do Sul, 2015.

MINAYO, M. C. S.; SANCHES, O. Quantitativo-qualitativo: oposição ou complementariedade? Cadernos de Saúde Pública, v. 9, n. 3, 1993, p. 239-262.

OLIVEIRA, A. V. O imperativo da mudança no ensino da Literatura: repensando os métodos a partir de termos geradores. Revista Prática Docente, v. 1, n. 1, 2016, p. 54-66.

OLIVEIRA, E. K. Corpo a corpo com o texto literário. 2009. 167 f. Tese (Doutorado em Teoria e História Literária). Instituto de Estudos da Linguagem, Universidade Estadual de Campinas/SP, 2009.

OLIVEIRA, E. K. Corpo a corpo com o texto na formação do leitor literário. Campinas/SP: Autores Associados, 2012.

OLIVEIRA, M. R. D. Explorando o território da voz e da escrita poética em Paul Zumthor. Revista Fronteira Z, São Paulo, n. 9, dezembro de 2012.

OLIVEIRA, M. M. Como fazer pesquisa qualitativa. Recife/PE: Ed. Bagaço, 2005

PEREIRA, A. S. de S. Ensino de Língua Portuguesa com base em gêneros textuais. Redenção, Ceará: Subprojeto PIBID - Letras - Ceará. Universidade da Integração Internacional da Lusofonia Afro-Brasileira, 2018.

Disponível em: http://pibid.unilab.edu.br/subprojetos/pedagogia-lingua-portuguesa/lingua-portuguesa-ce/ Acesso em: 15 jan. de 2020.

SILVA, F. G. et al. A poesia como recurso didático para a formação literária e sociocultural dos alunos do ensino médio. In: CONGRESSO NACIONAL DE EDUCAÇÃO, 3, 2016. Ceará: UECE, 2016, p. 1-8

SILVA, F. G. et al. Saraus contemporâneos: a importância dos saraus como espaço político de socialização. Cadernos CESPUC. Belo Horizonte/MG, n. 29, 2017, p. 150-167.

VIOLIN, A. C. Resenha: corpo a corpo com o texto com o texto no ensino de literatura. Revista Crátilo, v. 6, n. 2, 2013, p.102-104.

ZAPPONE, M. H. Y. Estética da Recepção. In: BONNICI, T.; ZOLIN, L. O. (Orgs.). Teoria literária: abordagem histórica e tendências contemporâneas. Maringá/PR: Eduem, 2009, p. $153-162$. 